\title{
Experimental Investigation of Premixed Turbulent Combustion in High Reynolds Number Regimes using PLIF
}

\author{
Jacob E. Temme ${ }^{1}$, Timothy M. Wabel ${ }^{2}$, Aaron W. Skiba ${ }^{3}$, and James F. Driscoll ${ }^{4}$ \\ University of Michigan, Ann Arbor MI 48109
}

\begin{abstract}
Premixed turbulent flame structures are imaged with simultaneous formaldehyde and OH PLIF. A new piloted burner was designed to achieve high turbulent Reynolds numbers $\left(\operatorname{Re}_{t}\right)$ up to 68,000 and low Damköhler numbers $\left(\mathrm{Da}_{\mathrm{t}}\right)$. Primary reaction zones are identified by the overlap of the $\mathrm{OH}$ and formaldehyde signals and preheat zones of low temperature secondary reactions are identified from the formaldehyde signal. At low $\mathrm{Re}_{\mathrm{t}}$ of 600 , the primary reaction zones are continuous and products do not mix with reactants. This results in thin preheat layers and relatively thin flamelets. $A s R_{t}$ increases, the primary reaction zones become shredded and disconnected. This allows mixing of the hot products with the reactants and broadens the preheat/secondary reaction zones. Additionally, the reaction layers are typically 4-5 times thicker than those in a laminar flamelet. Interestingly, as $\mathbf{R e}_{t}$ increases further, the thickness of the reaction layers only increases slowly, but the total area of reaction regions grows rapidly.
\end{abstract}

\section{Introduction}

$\mathrm{T}$ HERE are several gaps in our fundamental understanding of the physics of premixed turbulent flames. Many previous studies ${ }^{1-10}$ have been conducted at large turbulence intensities $\left(\mathrm{u}^{\prime} / \mathrm{S}_{\mathrm{L}}\right)$ but at small values of integral scale ( $\lambda$, which usually is normalized by laminar flame thickness $\delta$ ). The r.m.s. velocity fluctuation is $u^{\prime}$ and $S_{L}$ is the unstretched laminar burning velocity. However in many realistic devices it is the product of $u$ ' and $\lambda$ that is large. Therefore the present work focuses on the regime of large turbulence Reynolds numbers $\left(\mathrm{Re}_{\mathrm{t}}\right)$ and small Damköhler numbers $\left(\mathrm{Da}_{\mathrm{t}}\right)$ where:

$$
\begin{gathered}
\mathrm{Re}_{\mathrm{t}}=\mathrm{u}^{\prime} \lambda / v \\
\mathrm{Da}_{\mathrm{t}}=\left[\mathrm{S}_{\mathrm{L}}{ }^{2} / \mathrm{v}\right] /\left[\mathrm{u}^{\prime} / \lambda\right]
\end{gathered}
$$

The kinematic viscosity is $v$. It is known that high $\mathrm{Re}_{\mathrm{t}}$ increases the range of eddy sizes as well as the rotational velocity of eddies of a given size. Previous imaging of flame structure was done primarily for $\mathrm{Re}_{\mathrm{t}}$ less than $2,000^{1-12}$. Flamelets were found to exist and the flame surface nearly always was continuous; no holes were observed. There have been some studies that have extended $\mathrm{Re}_{\mathrm{t}}$ into the range of 2,000 to 5,500 ; including those of Dunn et al. ${ }^{13,14}$, and Shepherd et al. ${ }^{15}$.

However, prior to the present work, no data base has existed for $\mathrm{Re}_{\mathrm{t}}$ above 5,500. Shown below in Figure 1 is an adapted version of the regime diagrams of R. Borghi ${ }^{16}$, N. Peters ${ }^{17}$, and F. Williams ${ }^{18}$. The work presented here focuses on high $\mathrm{Re}_{t}$ conditions in which both $\mathrm{u}^{\prime}$ and $\lambda$ are large. Operation of the present burner at $\mathrm{Re}_{\mathrm{t}}$ of 23,000 necessitated an integral scale of $31 \mathrm{~mm}$, a u' value of $11.2 \mathrm{~m} / \mathrm{s}$ and a mean velocity of $25 \mathrm{~m} / \mathrm{s}$. New physics can occur at high $\mathrm{Re}_{\mathrm{t}}$ because when both $\mathrm{u}^{\prime}$ and $\lambda$ are sufficiently large there will be a larger range of eddy sizes, and the smaller eddies will be relatively strong. At low $\mathrm{Re}_{\mathrm{t}} \mathrm{small}$

\footnotetext{
${ }^{1}$ Post-Doctoral Research Fellow, Department of Aerospace Engineering, AIAA Member

${ }^{2}$ Research Assistant, Department of Aerospace Engineering, AIAA Member

${ }^{3}$ Research Assistant, Department of Aerospace Engineering, AIAA Member

${ }^{4}$ Professor, Department of Aerospace Engineering, AIAA Fellow
} 
eddies of size $\left(\delta_{\mathrm{f}}\right)$ may fit inside a preheat zone of thickness $\delta_{\mathrm{f}}$, but the eddies may not be strong enough to create a turbulent diffusivity $\left(\mathrm{u}_{\mathrm{p}}^{\prime} \cdot \delta_{\mathrm{f}}\right)$ that exceeds the molecular thermal diffusivity $(\alpha)$.

Some conflicting previous measurements have been reported. Increasing the turbulence sometimes makes flamelets thinner ${ }^{2,3}$, due to increased strain rate. Other studies ${ }^{4,13,14}$ report a 2-3 fold thickening of flamelets while Ratner and Driscoll ${ }^{19}$ showed that flamelets became shredded. One Damköhler number might determine the onset of flamelet broadening and a second one might determine the onset of shredding. Thus a flame could become shredded before it is broadened. Shredding of flamelets allows reactants to mix with hot products, which can create distributed reactions ${ }^{13,14,20-23}$.

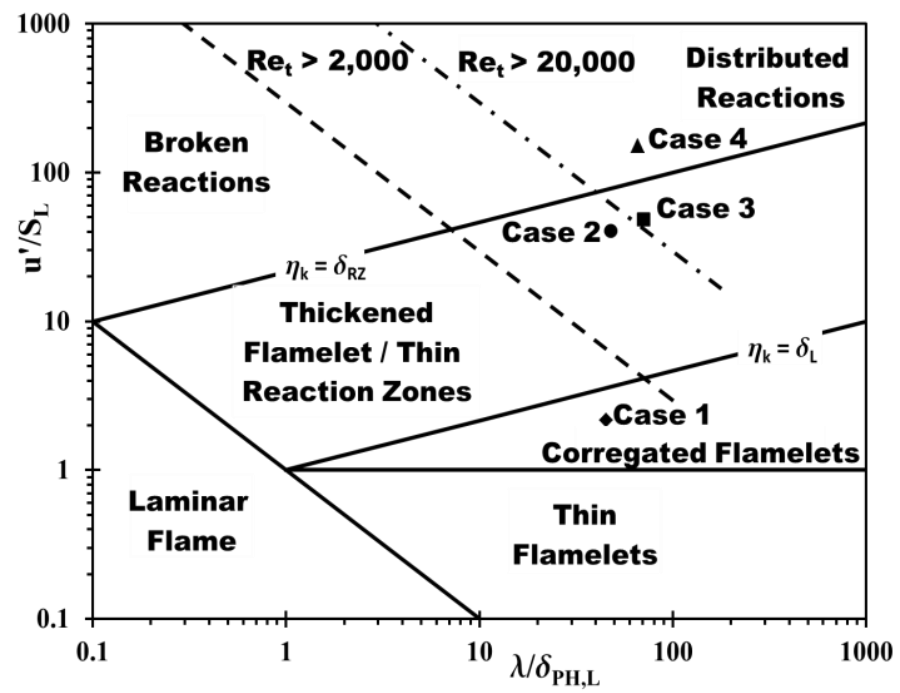

Figure 1. Regimes of Turbulent Premixed Combustion [Borghi ${ }^{16}$, and Peters ${ }^{17}$ ].

\section{Experimental arrangement}

The Michigan Hi-Pilot Burner is shown in Figure 2 below.
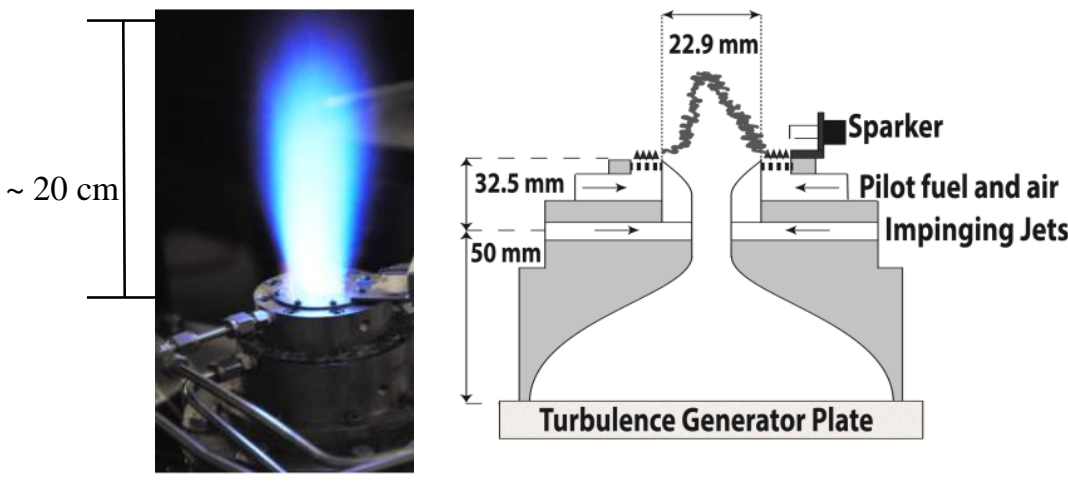

Figure 2. Michigan Hi-Pilot Burner operated at

$$
\mathbf{R e}_{+}=25.000
$$

The Hi-Pilot Burner provides a turbulence level (u') and an integral scale $(\lambda)$ that are uniform in space. Uniform u' and $\lambda$ avoids ambiguities as to where conditions lie on the regime diagram. To prevent flashback the walls diverge so that gas velocities increase in the upstream direction. Turbulence is created by impinging jets of reactants at the throat and a slotted-contraction device ${ }^{28,29}$.

Operating conditions are listed in Table 1 below.

\begin{tabular}{ccccccccc} 
Case & $\mathrm{U}$ & $\mathrm{u}^{\prime}$ & $\lambda$ & $\mathrm{Re}_{\mathrm{t}}$ & $\mathrm{Da}_{\mathrm{t}}$ & $\mathrm{u}^{\prime} / \mathrm{S}_{\mathrm{L}}$ & $\lambda / \delta_{\mathrm{PH}, \mathrm{L}}$ & $\varphi$ \\
\hline 1 & $5 \mathrm{~m} / \mathrm{s}$ & $0.5 \mathrm{~m} / \mathrm{s}$ & $20 \mathrm{~mm}$ & 600 & 134 & 2 & 43 & 0.75 \\
2 & $19 \mathrm{~m} / \mathrm{s}$ & $9.4 \mathrm{~m} / \mathrm{s}$ & $21 \mathrm{~mm}$ & 13100 & 7.9 & 41 & 48 & 0.75 \\
$2 \mathrm{a}$ & $19 \mathrm{~m} / \mathrm{s}$ & $9.4 \mathrm{~m} / \mathrm{s}$ & $21 \mathrm{~mm}$ & 13100 & 2.2 & 78 & 29 & 0.6 \\
3 & $25 \mathrm{~m} / \mathrm{s}$ & $11.2 \mathrm{~m} / \mathrm{s}$ & $31 \mathrm{~mm}$ & 23000 & 9.7 & 49 & 70 & 0.75 \\
$3 \mathrm{a}$ & $25 \mathrm{~m} / \mathrm{s}$ & $11.2 \mathrm{~m} / \mathrm{s}$ & $31 \mathrm{~mm}$ & 23000 & 1.6 & 122 & 34 & 0.6 \\
4 & $49 \mathrm{~m} / \mathrm{s}$ & $35 \mathrm{~m} / \mathrm{s}$ & $29 \mathrm{~mm}$ & 68000 & 2.9 & 152 & 65 & 0.75
\end{tabular}

Table 1. Operating conditions for methane-air combustion, $T_{1}=300 \mathrm{~K}, p=1 \mathrm{~atm}$. 
Simultaneous formaldehyde-OH PLIF images were acquired by Andor intensified CCD cameras using two Spectra-Physics Nd:YAG lasers and a Syrah dye laser to create laser sheets at $355 \mathrm{~nm}$ and $283 \mathrm{~nm}$. A diagram depicting our simultaneous PLIF imaging setup is provided below in Figure 3.

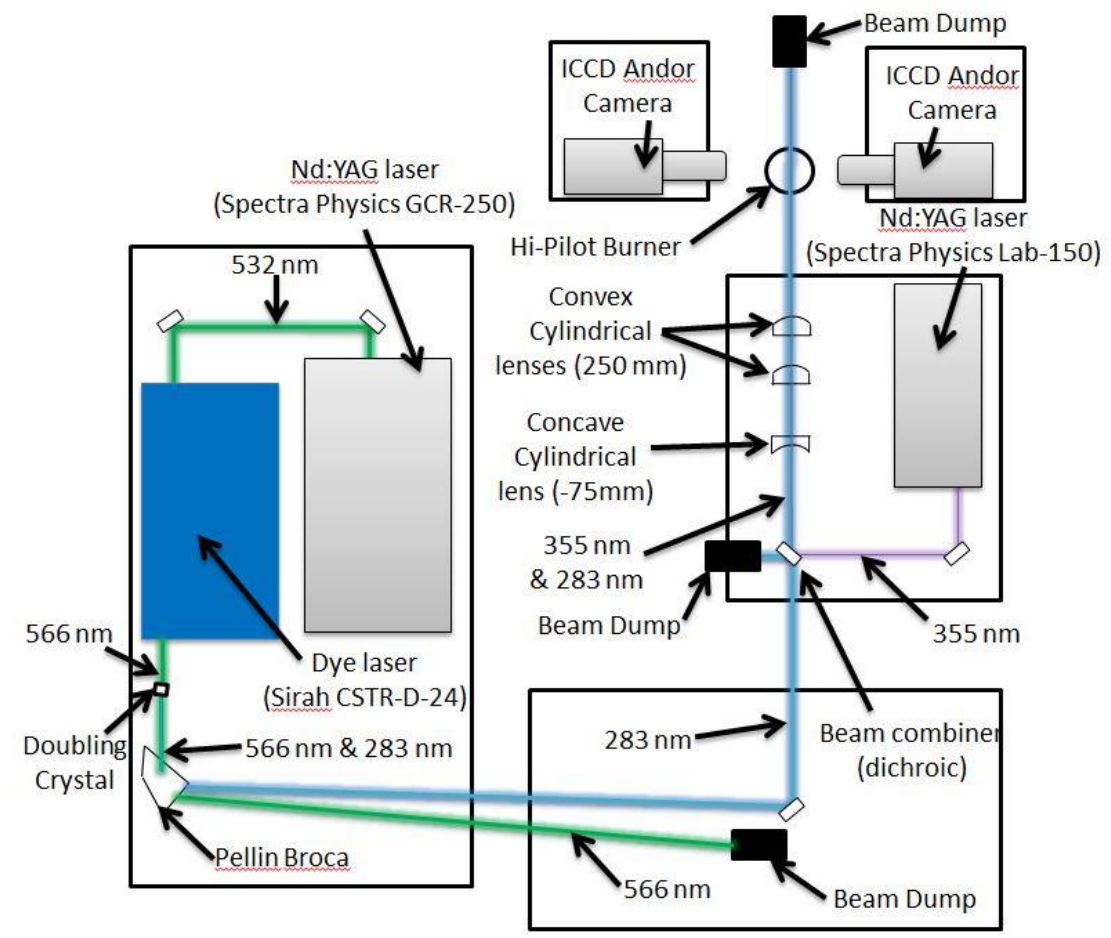

Figure 3. Schematic of the imaging system used to attain Simultaneous PLIF images of $\mathrm{CH}_{2} \mathrm{O}$ and $\mathrm{OH}$.

Turbulence levels and integral scales were measured with a LaVision PIV system. The thickness of the reaction zone is defined to be the full width-half maximum of the heat release rate curve. Figure 4 shows CHEMKIN profiles calculated for a laminar premixed methane-air flame $(\phi=$ 0.75 ). The reaction zone thickness is defined to be the width of the formaldehyde-OH overlap layer, based on its full-width at $85 \%$ maximum; $85 \%$ was selected because lower values were lost when noise reduction filtering was applied. Previous studies ${ }^{20-27,30-34}$ also have used the overlap of $\mathrm{OH}$ and formaldehyde or $\mathrm{HCO}$ to define the reaction layer. The preheat zone thickness is defined as the distance between the $20 \%$ point on the formaldehyde curve $(\mathrm{T}=400 \mathrm{~K})$ and the edge of the formaldehyde $\mathrm{x} \mathrm{OH}$ curve. For each formaldehyde PLIF image, edge detection was used to remove background noise and the normal to each edge was determined. The distance from one edge to the other, along the normal direction, was

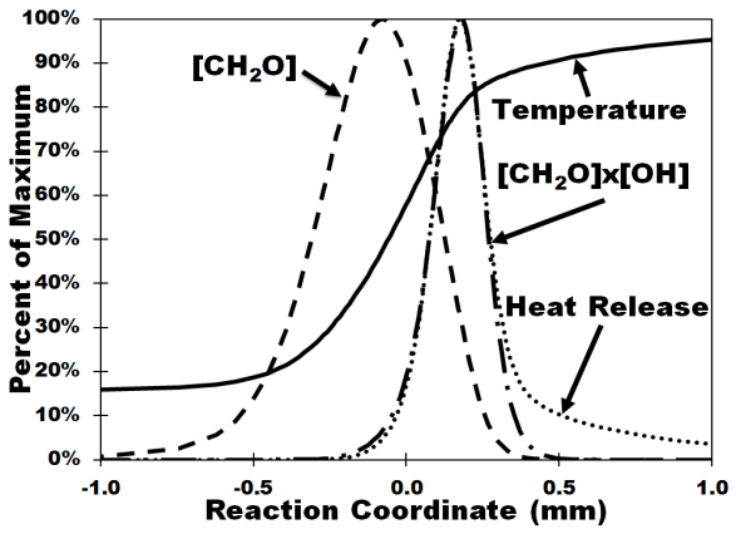

Figure 4. CHEMKIN laminar flame computations showing that formaldehyde marks the preheat zone while the overlap of formaldehyde- $\mathrm{OH}$ region marks the reaction zone. recorded. 


\section{Results}

This section displays and discusses the results from the simultaneous formaldehyde-OH PLIF images take at four different $\mathrm{Re}_{\mathrm{t}}$.

\section{A. Preheat zone structure and thickness}

Figure 5 shows some instantaneous preheat zones that begin where the PLIF signal exceeds $20 \%$ of its maximum value $(\mathrm{T}=400 \mathrm{~K})$. Case 1 , which has low $\mathrm{Re}_{t}$ conditions (see Table 1 ) and is shown in Figure 5a, exhibits thin and continuous flamelets. It is concluded that because small pockets and cusps also are observed, Case 1 lies in the corrugated flamelet regime. The mean flamelet preheat zone thickness $\left(\delta_{\mathrm{PH}}\right)$, averaged over 200 images, is $0.55 \mathrm{~mm}$. The preheat zone thickness $\delta_{\mathrm{PH}, \mathrm{L}}$ for an unstretched laminar flame, based on CHEMKIN results, is $0.44 \mathrm{~mm}$, so $\delta_{\mathrm{PH}} / \delta_{\mathrm{PH}, \mathrm{L}}$ is 1.25 for Case 1.

At higher Reynolds numbers, Figures $5 \mathrm{~b}$ and $5 \mathrm{c}$ show that preheat regions are much thicker than in Figure 5a. The mean preheat zone thicknesses are listed in Table 1. For Cases 2, 3, and 4 mean values of $\delta_{\mathrm{PH}}$ are $2.1 \mathrm{~mm}$, $2.2 \mathrm{~mm}$, and $2.1 \mathrm{~mm}$, respectively. The corresponding values of $\delta_{\mathrm{PH}} / \delta_{\mathrm{L}}$ are 4.4, 4.5, and 4.7. Figure 6 is a plot of these values; each data point is the

A)

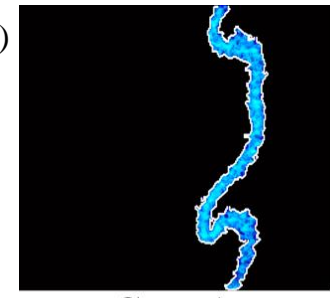

Case 1

C)

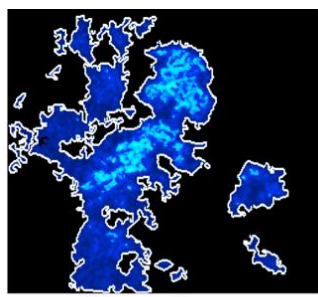

Case 3

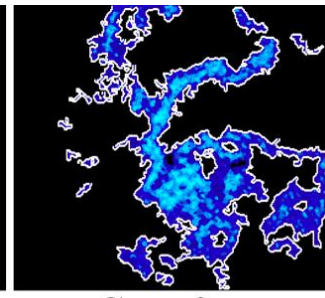

Case 2

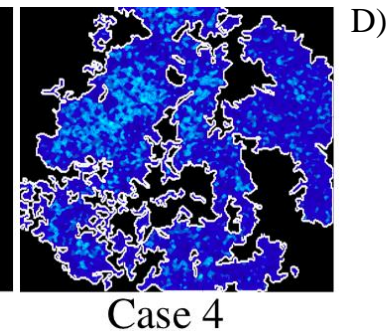

Case 4

B)

Figure 5. Preheat zone identified from formaldehyde PLIF images for Cases 1-4; conditions are listed in Table 1.

Methane-air, $\varphi=0.75$, reactants flow vertically upward. Field of view is $25 \mathrm{~mm}$ by $25 \mathrm{~mm}$. mean of 20,000 values obtained from 200 images. Figure 6 shows that the normalized thickness of the preheat zone rises rapidly from unity to 4.4 at $\mathrm{Re}_{\mathrm{t}}=13,100$ but it does not increase much at higher $\mathrm{Re}_{\mathrm{t}}$. What changes thereafter is the shape of the preheat zone. Figure 7 shows that increasing $\mathrm{Re}_{\mathrm{t}}$ causes the disappearance of preheat zone structures that are thin (between 1.0 and 1.5 times the laminar value $\delta_{\mathrm{PH}, \mathrm{L}}$ ). This also was observed in Figure 5; Figure $5 \mathrm{~b}$ shows that for Case 2 there are both thin layers $\left(\delta_{\mathrm{PH}}=1.5 \delta_{\mathrm{PH}, \mathrm{L}}\right)$ and thick layers $\left(\delta_{\mathrm{PH}}=4-5 \delta_{\mathrm{PH}, \mathrm{L}}\right)$. Figures $5 \mathrm{c}$ and $5 \mathrm{~d}$ display no thin layers.

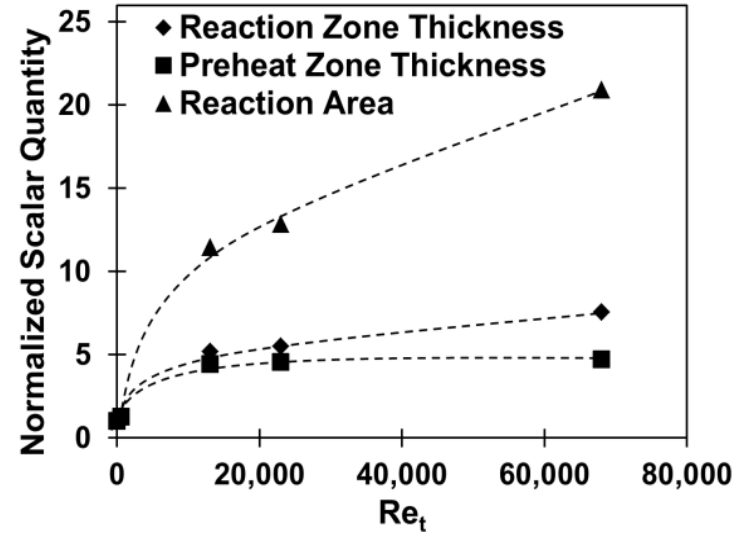

Figure 6. Measured thicknesses of preheat and reaction zones versus turbulence Reynolds number.

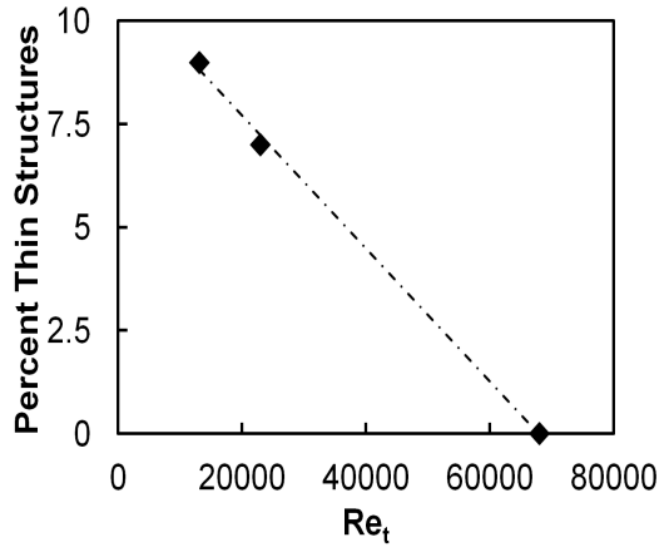

Figure 7: Percentage of thin "laminar-like" preheat zone layers having $\delta_{\mathrm{PH}} / \delta_{\mathrm{PH}}$ between 1.0 and 1.5. 


\section{B. Reaction zone structure and thickness}

Instantaneous images of reaction zones appear in Figure 8 below. The reaction zone (yellow) is where the overlap of the formaldehyde and the $\mathrm{OH}$ signals occur. Values are $0.47 \mathrm{~mm}, 0.50 \mathrm{~mm}$ and 0.68 $\mathrm{mm}$ for Cases 2, 3 and 4. Values of $\delta_{\mathrm{RZ}} / \delta_{\mathrm{RZ}, \mathrm{L}}$ were 5.2, 5.5 and 7.6. The laminar value from CHEMIKN $\delta_{\mathrm{RZ}, \mathrm{L}}$ is $0.09 \mathrm{~mm}$. Figure 6 shows that reaction zone thickness increases rapidly up to $\mathrm{Re}_{\mathrm{t}}=13,100$ and only gradually thereafter.
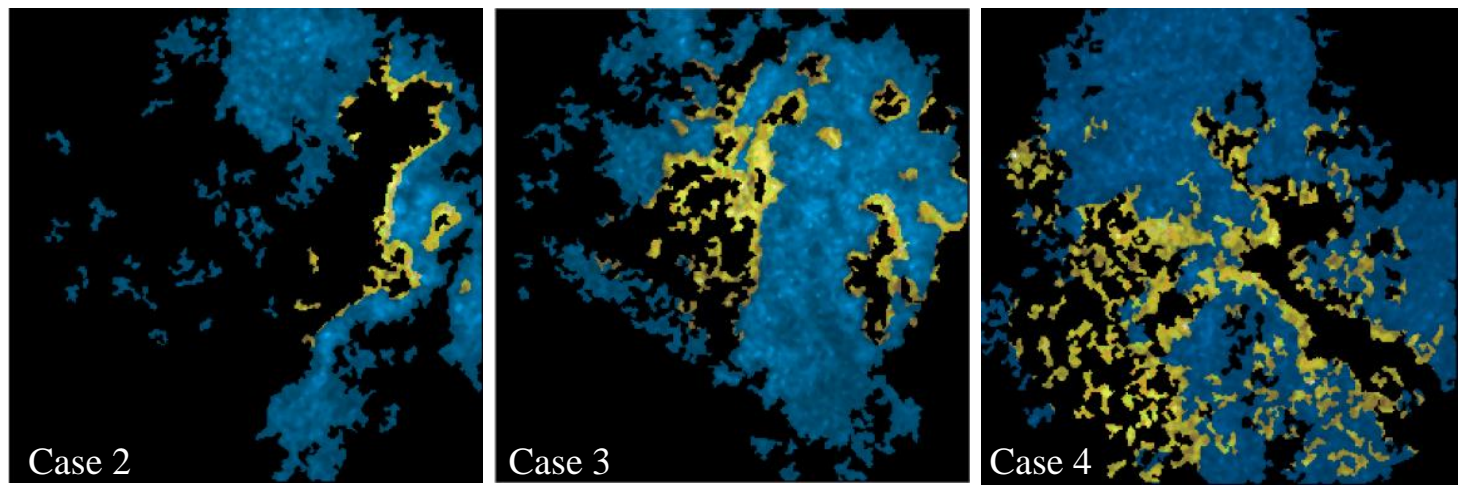

Figure 8. Preheat zone (blue) and reaction zone (yellow) for Case 2,3, and 4; conditions listed in Table 1. Preheat zone is where formaldehyde signal is observed; reaction zone is where the overlap of formaldehyde and $\mathrm{OH}$ signals occurs. Flow centerline is at the right hand side and flow direction is up. Field of view is $25 \mathrm{~mm}$ by $25 \mathrm{~mm}$.

A surprising finding is that the total area of the reaction zones (the upper curve in Figure 6) can be seen to increase rapidly with $\mathrm{Re}_{\mathrm{t}}$. This reaction zone area, $A_{\mathrm{RZ}}$, was calculated by summing the pixel area for all reaction zones in a PLIF frame. These values are compared to the area of a nominal laminar flame with reaction zone width of $0.09 \mathrm{~mm}$ and height of the entire frame. Values for $A_{R Z} / A_{R Z, L}$ were 11.5, 12.8, and 20.9 respectively.

It is concluded that the highest $\mathrm{Re}_{\mathrm{t}}$ case (Case 4) lies entirely in the "distributed reaction" regime. Figure 8c shows that reaction regions are distributed in space and the area of the reaction zone is 20.9 times that of an unwrinkled laminar flamelet (Figure 6). Shredding causes the combustion to become more compact. It was observed that as soon as local extinction occurs there is immediate broadening of both the preheat and reaction regions. This implies that the mixing of hot products and reactants (near the "holes") is one cause of the thickening. As $\mathrm{Re}_{t}$ is increased a shredded flame leads to a distributed reaction. The role of auto ignition is expected to become important in these latter two cases. Case 2 displays both thickened flamelets as well as fully distributed regions, so it appears to be on the regime boundary.

\section{Effect of varying equivalence ratio}

Table 2 show the preliminary results of the effects of equivalence ratio on the turbulent flame regions.

\begin{tabular}{cccc}
$\varphi$ & $\delta_{\mathrm{PH}} / \delta_{\mathrm{PH}, \mathrm{L}}$ & $\delta_{\mathrm{RZ}} / \delta_{\mathrm{RZ}, \mathrm{L}}$ & $\mathrm{A}_{\mathrm{RZ}} / \mathrm{A}_{\mathrm{RZ}, \mathrm{L}}$ \\
\hline 0.75 & 4.5 & 5.0 & 12.0 \\
0.6 & 1.8 & 3.0 & 4.0
\end{tabular}

Table 2. Variations in $\delta_{\mathrm{PH}}, \boldsymbol{\delta}_{\mathrm{RZ}}$, and $\mathrm{A}_{\mathrm{RZ}}$ for two different equivalence ratios.

Contrary to expectations, the normalized reaction zone and preheat zone thickness decreased with decreasing equivalence ratio. Similarly, the normalized reaction zone area also decreased. It is not clear if this result is an artifact of the experimental setup or a true physical phenomenon. More experiments with a wider variance of equivalence ratios are being conducted to further investigate this trend. 


\section{Conclusion}

1) For a moderate $\mathrm{Re}_{\mathrm{t}}$ of 600 (Case 1) thin flamelets were observed whose average preheat zone thickness was 1.25 times that of a laminar flamelet. Some of the thickening occurs near segments of high curvature, such as cusps.

2) For larger $\mathrm{Re}_{t}$ of 13,100 (Case 2) significant shredding of the reaction layers occurs along with major thickening of both preheat and reaction zones, such that $\delta_{\mathrm{PH}} / \delta_{\mathrm{PHL}}=4.4$ and $\delta_{\mathrm{RZ}} / \delta_{\mathrm{RZL}}=5.2$. As $\mathrm{Re}_{\mathrm{t}}$ is further increased to 23,000 (Case 3) and 68,000 (Case 4) the preheat and the reaction zones continue to thicken, reaching values of $\delta_{\mathrm{PH}} / \delta_{\mathrm{PHL}}=4.5$ and $\delta_{\mathrm{RZ}} / \delta_{\mathrm{RZL}}=5.5$ for Case 3 and $\delta_{\mathrm{PH}} / \delta_{\mathrm{PHL}}=4.7$ and $\delta_{\mathrm{RZ}}$ $/ \delta_{\mathrm{RZL}}=7.6$ for Case 4 . The total amount of reactions was seen to increase and the reaction zone area was quantified. Normalized areas of 11.5, 12.8, and 20.9 were recorded.

3) The thick distributed preheat and reaction regions begin to occur when the reaction layers begin to become shredded and large holes appear. The distributed reaction regions are best explained by the mixing of hot products with the reactants near the holes in the reaction regions, which would allow auto-ignition to occur over a large region.

4) The highest $\mathrm{Re}_{t}$ case (Case 4) lies in the distributed reaction regime. Reactions are seen to occur somewhat uniformly over a wide region in space. The average area of the reaction region exceeds twenty times that of a flamelet.

5) Initial results of equivalence ratio dependence suggest that decreasing equivalence ratios lead to decreasing turbulent flame zone thicknesses. More experiments with a wider variation of equivalence ratios are needed to verify this phenomenon.

\section{Acknowledgements}

Support for this research was provided by AFOSR Grant FA9550-12-1- 0101 that was monitored by Dr. Chiping Li.

\section{References}

${ }^{1}$ I.G. Shepherd, R. K. Cheng, Combust. Flame 127 (2001) 2066-2075.

${ }^{2}$ A. Buschmann, F. Dinkelacker, T. Schafer, M. Schafer, J. Wolfrum, J.. Proc Combust. Inst. 26 (1996) 437-445.

${ }^{3}$ A. Soika, F. Dinkelacker, A. Leipertz, Proc. Combust. Inst . 27 (1998) 785-792.

${ }^{4}$ Y.-C. Chen, R. W. Bilger, Combust. Flame 131(2002) 400-435.

${ }^{5}$ J. F. Driscoll, Prog. Energy \& Combust. Sci. 34 (2008) 91-134.

${ }^{6}$ A. M. Steinberg, J. F. Driscoll, Combust. Flame 157 (2010) 1422-1435.

${ }^{7}$ A. M. Steinberg, J. F. Driscoll, Expts. in Fluids 47 (2009) 527-547.

${ }^{8}$ J. B. Bell, M.S. Day, J. F. Grcar, M.J. Lijewski, J. F. Driscoll, S. Filatyev, Proc. Combust. Inst. 31 (2007) 12991307.

${ }^{9}$ H. Kobayashi, T. Kawahata, K. Seyama, T. Fujimari, J.S. Kim, Proc. Combust. Inst. 29 (2002) 1793-1800.

${ }^{10}$ R. Sankaran, E.R. Hawkes, J.H. Chen, JH., Proc, Combust, Inst, 31(2006)1291-1298.

${ }^{11}$ F.T.C. Yuen, O. Gulder, Proc. Combust. Inst. 34 (2013) 1393-1400.

${ }^{12}$ F.T.C. Yuen, O. Gulder, Combust. Sci. Technol. 182 (2010) 544-558.

${ }^{13}$ M.J. Dunn, A. R. Masri, R. W. Bilger, R.S. Barlow, G.S. Wang, Proc. Combust. Inst. 32 (2009) 1779-1786.

${ }^{14}$ M.J. Dunn, A. R. Masri, R. W. Bilger, R S. Barlow, Flow Turbulence Combust. 85 (2010) 621-648

${ }^{15}$ I.G. Shepherd, R.K. Cheng, T. Plessing, C. Kortschik, N. Peters N., Proc Combust. Inst. 29 (2002) 1833-1840.

${ }^{16}$ R. Borghi, Prog. Energy Combust. Sci. 14 (4) (1988) 245-292.

${ }^{17}$ N. Peters, Turbulent Combustion, Cambridge U. Press, Cambridge UK, 2000.

${ }^{18}$ F. A. Williams, Combust. Flame 26 (1976) 269-276. Also see Turns, S., An Introduction to Combustion, McGraw Hill Pub., N.Y. 2000.

${ }^{19}$ A. Ratner, J. F. Driscoll, J.M. Donbar, C.D. Carter, J.A. Mullin, Proc. Combust. Inst. 22 (2000) 245-251.

${ }^{20}$ C. Duwig, B. Li, Z. Li, M. Alden, Combust. Flame 159 (2012) 306-316.

${ }^{21}$ J. Sjoholm, J. Rosell, B. Li, M. Richter, Z. Li, X.-S. Bai, M. Alden, Proc. Combust. Inst. 34 (2013) 1475-1482.

${ }^{22}$ R. Geizendanner, O. Keck, P.Weigand, W. Meier, U. Meier, W.Stricker, M. Aigner, Combust. Sci. Technol. 175 (2003) 721-741.

${ }^{23}$ D. J. Micka, J. F. Driscoll, Combust. Flame 159 (2012) 1205-1214.

${ }^{24}$ A. Cavaliere, M. de Joannon, Prog. Energy Combust. Sci. 30 (2004) 329-366.

${ }^{25}$ A.Y. Poludnenko, E.S. Oran, Combust. Flame 157 (2010) 995-1006.

${ }^{26}$ A. J. Aspden, M. S. Day, J. B. Bell, J. Fluid Mech. 680 (2011) 287-320.

${ }^{27}$ J. Savre, H. Carlsson, X. S. Bai, Flow Turbulence Combust. 90 (2013) 325-341.

${ }^{28}$ A. Marshall, P. Venkateswaran, D. Noble, J. Seitzman, T. Lieuwen, Expt. Fluids 51 (2011) 611-620.

${ }^{29}$ B. Videto, D. Santavicca, Combust. Sci. Technol. 76 (1):159-164.

${ }^{30}$ B.O. Ayoola, R. Balachandran, J.H. Frank, E. Mastorakos, C.F. Kaminski, Combust. Flame 144 (2006) 1-16. 
${ }^{31}$ A. Fayoux, K. Zahringer, O. Gicquel,.C. Rolond, Proc. Combust. Inst. 30 (2005) 251-257.

${ }^{32}$ H.N. Najm, P.H. Paul, C.J. Mueller, P.S. Wyckoff, Combust. Flame 113 (1998) 312-332.

${ }^{33}$ C.M. Vagelopoulos, J.H. Frank, Proc. Combust. Inst. 30 (2004) 241-249.

${ }^{34}$ S. Böckle, J. Kazenwadel, T. Kunzelmann, D.-I. Shin, C. Schulz, J. Wolfrum, Proc. Combust. Inst. 28 (2000) 279286. 